\title{
O Cupido e o leitor: afetividade na mediação da leitura literária
}

\section{The Cupid and the reader: affectivity in the mediation of literary reading}

https://doi.org/10.34112/2317-0972a2018v36n74p47-58

\author{
Solange da Silva Souza ${ }^{1}$ \\ Paulo Demetrio Pomares da Silva ${ }^{2}$ \\ Nilo Carlos Pereira de Souza ${ }^{3}$
}

RESUMO: O presente artigo, resultante de uma investigação bibliográfica, tenta contribuir com reflexões sobre um componente que está presente em muitas das bem sucedidas experiências que promovem o encontro transformador com a leitura literária: a afetividade, algo que ao nosso entender passa muitas vezes despercebido como elemento partícipe do processo de constituição do leitor. Situando essa discussão no contexto educacional escolar, temos como inspiração teórica o fundador da psicologia histórico-cultural, Lev Semyonovich Vigotski (1896 - 1934). Para contribuir com tal argumentação, convidamos para esta "roda de leitura" Paulo Freire (1921 - 1997), grande representante brasileiro da teoria crítica da educação. Juntos a estes importantes teóricos, propomos pensar sobre o lugar das emoções na formação de leitores literários.

PALAVRAS-CHAVE: Leitura literária; formação do leitor literário; afetividade.

ABSTRACT: The present article, resulting from a bibliographic investigation, tries to contribute with reflections on a component that is present in many of the successful experiences that promote the transformative encounter with the literary reading: the affectivity, something that in our understanding often happens unnoticed like element participant of

1. Universidade Federal do Pará, Belém, PA, Brasil.

2. Universidade Federal do Pará, Belém, PA, Brasil.

3. Universidade Federal do Pará, Belém, PA, Brasil. 
the process of constitution of the reader. Placing this discussion in the school educational context, we have as theoretical inspiration the founder of historical-cultural psychology, Lev Semyonovich Vigotski (1896 - 1934). To contribute to this argument, we invited Paulo Freire (1921 - 1997), the great Brazilian representative of the critical theory of education, to this "reading wheel". Together with these important theorists, we propose to think about the place of the emotions in the formation of literary readers.

KEYWORDS: Literary reading; formation of the literary reader; affectivity.

\section{INTRODUÇÃO}

A educação escolar, enquanto atividade humana imensamente permeada pelas relações sociais estabelecidas em seu processo, jamais irá prescindir dos elementos que a caracterizam, entre os quais a afetividade, que exerce um papel de destaque no que se refere à formação do leitor literário. Como realizar um trabalho de leitura literária sem nenhum grau de envolvimento afetivo entre aquele que pretensamente deseja conquistar leitores para um tipo de texto tão subjetivo quanto o literário e um leitor em potencial?

A proposta para reflexão aqui desenvolvida é fruto de experiências realizadas ao longo do tempo no exercício de trabalhos de incentivo à leitura literária com crianças e também de questionamentos surgidos a partir de leituras sobre estudiosos da área educacional.

Entre os autores escolhidos para sustentar tal reflexão, destaca-se Vigotski ${ }^{4}$ (1896-1934), precursor da Teoria Histórico-Cultural, que tem na dimensão social do desenvolvimento humano um dos seus fundamentos. Para Vigotski (1997 apud PINO, 2005, p. 87), a natureza legítima do desenvolvimento humano é cultural. Isso não quer dizer que os estudos de Vigotski tenham negado a importância dos fatores biológicos no desenvolvimento do ser humano, mas sim que eles demostraram que “(...) toda educação tem inevitavelmente um caráter social (Vigotski, 2003, p. 75)”.

Partindo do princípio de que a formação de leitores passa pela atuação daqueles que a promovem, os sujeitos que assumem essa função recebem as mais variadas denominações: promotores, mediadores sociais, incentivadores e, por que não, "cupidos"? A figura mitológica que desperta o amor entre aqueles que por ela são

4. O nome do autor será grafado respeitando as formas utilizadas como referência. Quando não se tratar de uma referência específica, adotaremos a grafia traduzida "Vigotski". 
flechados é algo bastante similar aos que não medem esforços para unir leitores e livros. Nesse sentido, por meio de uma releitura do conto tradicional Eros e Psiquê (Apuleio, 2009), propomos buscar explicações que nos ajudem a responder a seguinte questão: se as experiências significativas de leitura podem estabelecer um vínculo afetivo entre leitor e livro, por que experiências organizadas por educadores, com a finalidade de promover a leitura literária, prescindiriam do mesmo vínculo?

Para contribuir com a análise da proposição apresentada, apontaremos alguns tópicos defendidos por estudiosos que compartilham a premissa de que a afetividade é um componente crucial para o desenvolvimento humano, para os processos educacionais escolarizados e, por que não dizer, também para aqueles que envolvem a mediação da leitura literária, permitindo assim que outros pontos possam ser discutidos a partir da reflexão pretendida.

\section{O Cupido: entre Leitores e LiVRos}

Na mitologia romana, o Cupido era o antigo deus do amor (correspondente a Eros na grega). Filho de Vênus (a deusa do amor e da beleza) e Mercúrio (o mensageiro dos deuses), não é difícil compreender o porquê de ter se tornado mensageiro do amor. Mas apesar de muito popular, nem todos sabem que ele próprio já foi alvo desse sentimento, além de ter descoberto variações do amor.

Um dia, Vênus, com inveja da belíssima e mortal Psiquê, pediu ao filho Cupido que a ferisse com uma das suas setas e a fizesse se apaixonar por um ser monstruoso, tornando-a infeliz para sempre. No entanto, um pequeno acidente fez com que o Cupido fosse ferido com sua própria seta, iniciando assim uma união que resultou em um amor feliz e eterno. Essa é a história oficial. Mas existem outros detalhes que nem todo mundo conhece... Dizem que depois disso Cupido virou um sujeito bastante amoroso e ainda mais distraído.

Cupido parece ser mesmo uma figura atrapalhada. Adora viver perto de gente que, à sua semelhança, ainda não perdeu a curiosidade pela vida; por isso, depois que conheceu a escola, esta se tornou o seu lugar favorito. Entretanto, é comum ele cometer alguns equívocos e errar seus alvos. Ele costuma andar (ou melhor, voar) entre as carteiras escolares e, às vezes, mesmo que a sua missão seja a de unir corações solitários nas escolas, ele fica distraído com algo que desperta o seu instinto curioso. 
Certa vez, Cupido estava exausto, já que havia passado o dia todo trabalhando. E, pela primeira vez, não queria entrar em nenhuma sala de aula. Procurava por um lugar vazio em que pudesse tirar uma sonequinha. A sua procura no interior da escola o levou a um espaço que ele ainda não conhecia. Havia nele vinte estantes e muitos livros. Mas Cupido achou o local um pouco triste, pois não viu muitos alunos ali. Cansado, procurou um cantinho em que não houvesse ninguém por perto, encostou sua cabecinha em uma estante e tirou seu cochilo almejado, mas, como as estantes não eram assim tão firmes, de repente, no momento melhor do seu sono, acordou com o peso de um objeto em seu colo e o rostinho maroto de uma criança à sua frente. $\mathrm{O}$ objeto era um livro que acabara de despencar de uma das prateleiras. A criança era um desses inquietos e curiosos leitores ávidos por mais uma história de aventuras, que, durante a sua busca nas estantes, havia deixado cair um livro justamente sobre o colo de Cupido.

Cupido ainda estava cansado, mas seu cansaço não era maior do que a sua curiosidade. Então, sem saber direito o que fazer com aquele livro em suas mãos, ficou observando atentamente as emoções demonstradas na face do garoto, que, sentado no chão, lia vorazmente o livro escolhido.

Nem é necessário dizer que Cupido passou longas horas por ali, retirando um livro atrás do outro das prateleiras. Ele queria experimentar as mesmas emoções que havia visto traduzidas nas expressões daquele menino: o espanto, a dúvida, a descoberta, $\mathrm{o}$ riso, a preocupação, a ansiedade. Todas aquelas nuances de sentimentos enxergadas naquela unidade (leitor e livro) despertaram nele uma vontade nunca antes sentida de querer descobrir também aquele mistério, viver aquela relação de completude.

Depois daquele dia, Cupido se esqueceu por completo de que sua tarefa era a de promover o encontro entre pessoas. Abandonou de vez suas flechas e passou a utilizar outras "armas", criando situações mirabolantes para aproximar alunos e livros. E sabem por que ele passou a fazer tudo isso? Havia também ele sido novamente alvejado por uma forma eterna de amor pelas histórias e pelos leitores que conquistou.

Como quem conta um conto, aumenta um ponto, não sabemos se isso tudo é verdade... mas ouvimos dizer...

2. Afetividade e mediação de leitura literária na escola.

A função de despertar o fascínio do leitor pelo texto literário ocorre pelo estabelecimento de um vínculo afetivo. O "cupido", nesse caso, não é simplesmente 
alguém que oferece um livro, como um mensageiro que somente entrega uma carta ou uma mensagem. Seu trabalho vai muito além. Configura-se uma mediação organizada, cuidadosamente planejada por alguém que age desse modo porque $o$ compartilhamento de leituras, em ambientes formais ou não formais de educação, pressupõe uma relação de cumplicidade entre os envolvidos.

Isso não só é comprovado empiricamente, como também pode ser sistematicamente percebido nos mais importantes teóricos do desenvolvimento humano. Apesar de, historicamente, a tradição científica da psicologia sempre demonstrar uma tendência a tratar separadamente as dimensões cognitivas e afetivas do ser humano, e, por sua vez, a escola sempre privilegiar as primeiras em detrimento das segundas, muitos autores já pesquisaram a relação entre afeto e cognição.

Lev Semyonovich Vygotsky (1896 - 1934), que teve em sua trajetória a marca da literatura, sempre foi interessado pela produção ficcional, tendo até trabalhado como crítico literário. O seu livro Psicologia da arte 5 inclui uma edição de sua monografia sobre Hamlet, de William Shakespeare. Mesmo tendo se graduado em Direito, Vigotski estudou paralelamente Literatura e História, mas seu interesse de pesquisador sempre foi a Psicologia. As análises críticas dos estudos psicológicos em curso na sua época tornaram Vigotski um pioneiro da Psicologia do desenvolvimento. $O$ resultado dos seus estudos até hoje tem grande influência no campo educacional.

Apesar de nunca ter usado em seus escritos o termo "cognição", Vigotski tratou dos processos internos de desenvolvimento do conhecimento pelo ser humano (nos seus aspectos de aquisição, organização e utilização), mas deu a esses processos denominações como "funções mentais" e "consciência". Em seus estudos, o teórico identificou dois tipos de funções mentais: as elementares (como atenção involuntária, mais relacionada a reflexos biológicos) e as superiores (atenção voluntária e memória lógica). No entanto, apesar de diferenciá-las, Oliveira (1992) alerta para o fato de que Vigotski concluiu que seria muito difícil compreendê-las como instâncias isoladas, uma vez que na sua essência são inter-relacionadas com as demais funções.

Antes de prosseguir, é necessário esclarecer um ponto importante do aspecto conceitual na obra teórica de Vigotski no que se refere à sua concepção sobre o papel dos instrumentos e dos signos na internalização das funções psicológicas superiores, que é o mesmo processo de formação da consciência: “[...] a analogia

5. Vigotski, L. S. Psicologia da arte. Trad. Paulo Bezerra. 2. ed. São Paulo: Martins Fontes, 20o1. (Originalmente publicado em 1925). 
básica entre signo e instrumento repousa na função mediadora que os caracteriza. Portanto, eles podem, a partir da perspectiva psicológica, ser incluídos na mesma categoria" (VIGOTSKI, 1991, p. 50).

Nesse sentido, Vigotski dá bastante importância aos processos de mediação simbólica, sobretudo nos estudos sobre linguagem. São os instrumentos e os sistemas de signos constituídos historicamente que fazem a mediação dos seres humanos entre si e deles com o mundo. Assim, pode-se inferir que, em um contexto escolar, o professor exerce um papel fundamentalmente diferenciado na organização dos mediadores simbólicos, visando à formação de leitores. Portanto, optamos por utilizar a expressão "leitor-educador", e não mediador, para nomear o docente que desenvolve atividades de leitura literária com o objetivo de formar leitores em ambiente escolar. Essa escolha visa apenas evitar confusões no entendimento, já que para Vigotski, o professor não seria um mediador, mas sim um organizador do ambiente de aprendizagem.

Em razão de sua abordagem teórica ser de caráter sistêmico, Vigotski sempre apontou como um dos principais pontos negativos da psicologia tradicional a divisão entre os aspectos intelectuais e afetivos, apresentando claramente, em várias das suas obras, a ideia unificadora entre as duas dimensões (cognitiva e afetiva) no funcionamento psicológico, e afirmando que

A forma de pensar, que junto com o sistema de conceito nos foi imposta pelo meio que nos rodeia, inclui também nossos sentimentos. Não sentimos simplesmente: o sentimento é percebido por nós sob a forma de ciúme, cólera, ultraje, ofensa. Se dizemos que desprezamos alguém, o fato de nomear os sentimentos faz com que estes variem, já que mantêm uma certa relação com nossos pensamentos (VYGOTSKY, 2004, p. 126).

Se "nós nos tornamos nós mesmos através dos outros" (VYGOTSKY apud PINO, 2000, p. 65), fica claro que o que vem dos outros e é por nós internalizado também inclui os sentimentos, e que a mediação da leitura literária, como qualquer outra atividade relacional humana, não irá prescindir das influências desses sentimentos no processo de formação de leitores.

Em "A formação social da mente", ao abordar as implicações práticas dos seus estudos sobre o desenvolvimento da linguagem escrita, Vigotski deixa claro que o ensino da leitura e da escrita na escola deve estar ligado às necessidades das crianças e ser relevante para sua vida. Logo, podemos inferir desse pensamento que a leitura 
não deve ser simplesmente um hábito que se realiza por incorporação, mas deve ser desenvolvida visando à sua própria internalização, a qual só acontece quando ela possui um significado intrínseco ao indivíduo e quando é ensinada naturalmente.

Vigostki indica ainda que tais situações naturais de "desenvolvimento organizado" (1991, p. 79) devem acontecer nas descobertas que ocorrem nas brincadeiras. Nessas circunstâncias, podemos deduzir a presença necessária da afetividade, uma vez que é imprescindível que o leitor-educador estabeleça uma aproximação natural com aqueles com quem está brincando. Quando são promovidas situações de aprendizagem em um contexto de naturalidade, todas as dimensões do desenvolvimento humano, incluindo as cognitivas e afetivas, estão presentes.

Ao se estabelecer um elo de afetividade entre leitor-educador (leitor experiente) e leitores em nível de desenvolvimento potencial, estes últimos se sentem confortáveis para se expressar livremente, contribuindo para uma compreensão real do uso da linguagem escrita em situações significativas de aprendizagem, ao contrário do que ocorre quando somente a habilidade motora é levada em conta. Vigotski apresenta críticas ao ensino da escrita como simples habilidade motora. Para ele, "ensina-se a criança a desenhar letras e a construir palavras com elas, mas não se ensina a linguagem escrita. Enfatiza-se de tal forma a mecânica de ler o que está escrito que acaba-se obscurecendo a linguagem escrita como tal” (1991, p.70).

As origens sociais do pensamento e da linguagem sempre foram reconhecidas por Vigotski no desenvolvimento humano. O ensaio escrito por Vera John-Steiner e Ellen Souberman, integrante do posfácio do livro A formação social da mente (VYGOTSKY, 1991, p. 86), trazem essa evidência:

Através do conceito da zona de desenvolvimento proximal defendido por Vygotsky durante os intensos debates sobre educação na década de 30, ele desenvolveu, do ponto de vista da instrução, os aspectos centrais da sua teoria da cognição: a transformação de um processo interpessoal (social) num processo intrapessoal, os estágios de internalização; o papel dos aprendizes mais experientes.

É perceptível que para Vigotski não há desenvolvimento humano significativo que não passe pelas experiências sociais. Na teoria histórico-cultural, o conceito de zona de desenvolvimento proximal talvez seja fundamental para compreendermos o papel da afetividade no processo de formação de leitores literários. (VYGOTSKY, 1984, p. 97, apud OLIVEIRA, 1997, p. 60). 
A zona de desenvolvimento proximal é a distância entre o nível de desenvolvimento real, que se costuma determinar através da solução independente de problemas, e o nível de desenvolvimento potencial, determinado através da solução de problemas sob a orientação de um adulto ou em colaboração com companheiros mais capazes (VYGOTSKY apud OLIVEIRA, 1997, p. 60).

Contextualizando, pode-se inferir que em um trabalho escolarizado de leitura literária, a presença do leitor-educador se faz fundamental para que o leitor iniciante atinja níveis mais significativos na experiência social da leitura. E para que este leitor experiente aproxime o leitor em potencial do nível de profundidade que se espera, ele deve se empenhar em tal aproximação, realizando com o aluno o percurso necessário, segurando-lhe as mãos e percorrendo com ele o caminho da leitura, ao invés de apenas permanecer no seu lugar, esperando que, sob suas distantes orientações, o leitor chegue até o livro.

Se fazemos alguma coisa com alegria as reações emocionais de alegria não significam nada senão que vamos continuar tentando fazer a mesma coisa. Se fazemos algo com repulsa isso significa que no futuro procuraremos por todos os meios interromper essas ocupações. Por outras palavras, o novo omento que as emoções inserem no comportamento consiste inteiramente na regulagem das reações pelo organismo (VIGOTSKI, 2001, p. 139).

Da mesma forma, Paulo Freire (1921-1997), educador brasileiro que enxergava na humanização um ponto fundamental para a concretização de uma educação libertadora, partindo do universo real dos alunos (linguagem já utilizada por eles) para se aproximar do desenvolvimento potencial a ser alcançado, sugeria algo semelhante ao proposto por Vigotski.

Não há, porém, humanização na opressão, assim como não pode haver desumanização na verdadeira libertação. Mas, por outro lado, a libertação não se dá dentro da consciência dos homens, isolada do mundo, senão na práxis dos homens dentro da história que, implicando a relação consciência-mundo, envolve a consciência crítica desta relação (FREIRE, 2011, p. 159). 
Constatamos na obra de Paulo Freire a mesma importância dada por Vigotski à dimensão social intrínseca à educação, uma vez que ambos compreendiam o processo de construção do conhecimento como resultado da interação entre sujeitos historicamente situados e o ambiente sociocultural onde vivem.

Partindo da convicção de ser o ato de ensinar uma especificidade humana, Freire é bastante explícito ao enumerar e analisar cada uma das exigências de uma prática educativa verdadeiramente autônoma, e, portanto, libertadora. Entre tais exigências destaca a afetividade como algo imprescindível à ação docente, fazendo um importante alerta àqueles que ainda acreditam que seriedade e afetividade na experiência pedagógica são inconciliáveis:

Na verdade, preciso descartar como falsa a separação radical entre seriedade docente e afetividade. Não é certo, sobretudo do ponto de vista democrático, que serei tão melhor professor quanto mais severo, mais frio, mais distante e "cinzento" me ponha nas minhas relações com os alunos, no trato dos objetos cognoscíveis que devo ensinar. A afetividade não se acha excluída da cognoscibilidade (1996, p. 159-160).

Para conquistar leitores na escola é preciso que o leitor-educador defina desde o início o papel que irá desempenhar no processo de incentivo à leitura literária. Para isso, é necessário compreender que a mediação da leitura é uma relação que se constrói entre o leitor em nível potencial de desenvolvimento da leitura e o livro (texto literário). Mas é preciso compreender ainda que essa relação só se aprimora na medida em que se desenvolve com a presença essencial do educador, leitor experiente que irá atuar na zona de desenvolvimento proximal, na qual o aluno vai pouco a pouco se constituindo um leitor independente, com suas escolhas, opiniões e interpretações em relação às suas leituras. E o prazer despertado no compartilhamento de leituras, de que o afeto é parte integrante, contribui para o interesse em buscar cada vez mais novas experiências de leitura, fazendo da afetividade um componente fundamental entre os envolvidos nesse processo.

Podemos resumir a importância da relação professor - aluno na educação escolarizada pelas afirmações de Vigotski (2003, p. 300):

O professor deve viver na coletividade escolar como parte inseparável dela e, nesse sentido, as relações entre professor e aluno podem alcançar tal vigor, limpeza e elevação que não encontrarão nada igual em toda a gama social das relações humanas [...] Na própria 
natureza do processo educativo, em sua essência psicológica, está implícita a exigência de um contato e de uma interação com a vida que sejam o mais estreitos possível.

Não é possível, portanto, pensar em um trabalho educativo que tenha por objetivo a formação de leitores de um texto cuja natureza seja a própria vida, sem que os sujeitos envolvidos no processo de mediação (alunos e professores) não se percebam conectados a esta vida, com todas as nuances que a caracterizam.

\section{CONSIDERAÇÕES FINAIS}

Infelizmente, ainda persiste no meio docente a perspectiva não conciliatória entre afeto e razão. Talvez seja exagerado afirmar que uma das principais dificuldades na conquista de leitores literários em ambiente escolar seja a ausência de percepção sobre o caráter eminentemente social da educação, o que se converte na pouca (ou nenhu$\mathrm{ma}$ ) disposição por parte do educador para o encontro verdadeiro com o outro. No entanto, para quem está lendo este texto até aqui e atua na formação de leitores literários, parece inconcebível uma ação pedagógica que envolva algum tipo de mediação de leitura literária sem que o leitor-educador construa uma relação de cumplicidade e afeto com os leitores com os quais pretende compartilhar leituras de textos cuja carga grandiosa de subjetividade demanda habilidades intelectuais, estéticas e emocionais.

Se aquilo que Freire (1996, p. 165) denomina de "ditadura racionalista" e Vigotski (2003, p. 295) trata como "Pedagogia ascética" prejudicam, no meio escolar, a construção de conhecimentos de uma forma geral, podemos dizer que, no que se refere à formação de leitores literários, muito mais prejudiciais podem ser as consequências da perspectiva separatista das dimensões que são naturalmente interligadas (intelecto e afeto), uma vez que isso pode contribuir para o estabelecimento de práticas equivocadas de contato com o texto literário na escola. Tais práticas podem, muitas vezes, esvaziar o sentido das obras literárias, afastando, ao invés de aproximar, leitores e livros.

Vigotski nos faz um alerta sobre o enorme perigo de os educadores profissionais reduzirem suas práticas docentes a uma função instrumental de educação, distanciando-se demasiadamente do seu aluno e seu universo. O professor "começa a se sentir no papel de instrumento da educação, no papel de gramofone que não tem voz própria e canta o que o disco lhe indica (2003, p. 296)". Nesse sentido, para se constituir verdadeiramente um leitor-educador, é necessário que este se perceba como organizador do ambiente social, que para Vigotski compreende o "único fator educativo" (2003, p. 
296). Logo, se o ambiente social é ponto crucial para a aprendizagem, a relação com o outro comporta todas as dimensões da vivência social, entre as quais a afetividade, e mais do que isso: revela-se um diferencial positivo na medida em que contribui para o interesse pela leitura, como tentamos demonstrar ao longo do texto.

Esperamos ter oferecido contribuições para a reflexão sobre a relação existente entre o modo como o leitor-educador enxerga seu papel no processo educacional e na formação de leitores de literatura, tendo como mote a afetividade. É evidente que muito mais aspectos poderiam ser trazidos para esta análise, mas, como uma proposta inicial de reflexão (e de provocação), o texto espera ter suscitado um olhar mais demorado sobre o espaço do afeto na relação entre este "cupido" e os futuros leitores que pretende conquistar, não para si, mas para o mundo pelo qual ele também se descobriu apaixonado.

\section{REFERÊNCIAS}

APULEIO. Eros e Psiquê. Trad. Ferreira Gullar. São Paulo: FTD, 2009.

FREIRE, Paulo. Ação cultural para a liberdade e outros escritos. 14. ed. rev. atual. Rio de Janeiro: Paz e Terra, 2011. 1996.

. Pedagogia da autonomia: saberes necessários à prática educativa. São Paulo: Paz e Terra,

OLIVEIRA, Ivone Martins de. Nas fronteiras entre o biológico e o cultural, o afeto. Cad. Cedes, Campinas, v. 35, n. especial, p. 375-389, out. 2015.

OLIVEIRA, Marta Kohl. O problema da afetividade em Vygotsky. In: LA TAILLE, Yves de. Piaget, Vygotsky e Wallon: teorias psicogenéticas em discussão. São Paulo: Summus, 1992.

OLIVEIRA, Marta Kohl. Vygotsky: aprendizado e desenvolvimento, um processo sócio-histórico. São Paulo: Scipione, 1997.

PINO, Angel. O social e o cultural na obra de Vigotski. Educação \& Sociedade, Campinas, ano XXI,

n. 71, p. 45-78, jul. 200o. Disponível em: <http://www.scielo.br/pdf/ccedes/v35nspe/1678-7110ccedes-35-spe-00375.pdf $>$. Acesso em: 19 dez. 2017.

VIGOTSKI, L.S. Manuscrito de 1929. Trad. Alexandra Marenitch. Educação \& Sociedade, ano XXI, n. 71, CEDES, p. 21-44, jul. 200o. Disponível em: <http://www.scielo.br/pdf/es/v2In7I/ a02V2I7I.pdf $>$. Acesso em: 23 dez. 2017.

. Psicologia pedagógica. São Paulo: Martins Fontes, 2001.

. Teoria e método em psicologia. 3. ed. São Paulo: Martins Fontes, 2004.

VYGOTSKY, L.S. A formação social da mente. São Paulo: Martins Fontes, 1991. Disponível em: <http://www.finom.edu.br/cursos/arquivos/2017822204529.pdf >. Acesso em: 22 dez. 2017. 
SOBRE OS AUTORES:

Solange da Silva Souza é graduada em Pedagogia (Universidade do Estado do Pará), especialista em Psicopedagogia (Universidade Cândido Mendes), é mestranda em Educação (Universidade Federal do Pará). É professora da Rede Municipal de Educação em Belém do Pará. Tem experiência na área de promoção à leitura em biblioteca escolar, com pesquisa nos seguintes temas: formação de leitores, mediação de leitura literária e biblioteca escolar.

E-mail: langinhass@gmail.com.

Paulo Demetrio Pomares da Silva é graduado em Letras (Universidade do Estado do Pará), é especialista em Metodologia do Ensino de Língua Portuguesa e Literatura pela Faculdade Internacional de Curitiba, é mestrando em Educação (Universidade Federal do Pará). É professor da Educação Básica da Rede Estadual - SEDUC - Pará e da Rede Municipal - SEMEC - Belém. Na SEMEC integra a Equipe Técnica do Ensino Fundamental (ETEF) desenvolvendo trabalhos de assessoramento e formação continuada de professores, contação de histórias e na realização de projetos que motivam alunos a práticas de leitura e escrita autoral, com pesquisa nos seguintes temas: Leitura, cultura e literatura de expressão amazônica e formação de leitores. E-mail:pddemetrios@hotmail.com.

Nilo Carlos Pereira de Souza é graduado em Letras e Artes (Universidade Federal do Pará), tem Mestrado em Letras - área de concentração Teoria Literária (Universidade Federal de Santa Catarina) e Doutorado em Letras - Teoria Literária (Universidade Federal de Santa Catarina). É professor Adjunto da Universidade Federal do Pará e professor do Programa de Pós-Graduação em Educação do Instituto de Ciências da Educação da UFPA. Tem experiência na área de Letras, com ênfase em Teoria Literária, atuando principalmente nos seguintes temas: Leitura Literária, Narrativas Contemporâneas, Formação de Leitor. É coordenador do Grupo de Estudos Literários na Amazônia e Formação de Leitor (GELAFOL), que desenvolve projetos de pesquisa e extensão sobre a leitura literária e formação de leitores em espaço escolar.

E-mail:nilocarlos7@gmail.com.

Recebido em o8 de abril de 2018 e aprovado em 18 de outubro de 2018. 